\title{
Association of IL-18 polymorphisms with rheumatoid arthritis: a meta-analysis
}

\author{
L.L. Li ${ }^{1}$, X.F. Deng ${ }^{2}$, J.P. Li ${ }^{3}$, N. Ning ${ }^{1}$, X.L. Hou ${ }^{1}$ and J.L. Chen ${ }^{1}$ \\ 1Department of Orthopedics, West China Hospital, Sichuan University, \\ Chengdu, China \\ ${ }^{2}$ Center of Organ Transplantation, Sichuan Provincial People's Hospital, \\ Chengdu, China \\ ${ }^{3}$ Department of Nursing, West China Hospital, Sichuan University, \\ Chengdu, China \\ Corresponding author: X.F. Deng \\ E-mail: doctordxf@163.com / doctordxf@qq.com
}

Genet. Mol. Res. 15 (1): gmr.15017389

Received August 6, 2015

Accepted November 6, 2015

Published January 22, 2016

DOI http://dx.doi.org/10.4238/gmr.15017389

\begin{abstract}
Interleukin-18 (IL-18), an important proinflammatory cytokine, has been reported to play a potential pathological role in rheumatoid arthritis (RA). Results from previous studies on the association between IL-18 polymorphisms and RA are conflicting. To clarify this, an updated meta-analysis of all available studies on IL-18 polymorphisms and RA was conducted. Eligible articles were identified by searching databases, including PubMed, Ovid, Cochrane Library, EMBASE, and China Knowledge Resource Integrated Database, for the period up to May 1, 2015. The pooled odds ratios (ORs) with $95 \%$ confidence intervals $(95 \% \mathrm{Cls})$ were used to assess the strength of association in the homozygote, heterozygote, dominant, recessive, and additive models. The software STATA (Version 13.0) was used for statistical analysis. Finally, 14 articles were included in the present meta-analysis. The IL-18 -607C/A polymorphism showed pooled ORs and $95 \% \mathrm{Cls}$ for the homozygote model (AA vs CC: $\mathrm{OR}=0.598 ; 95 \% \mathrm{Cl}=0.395-0.907$ ), and the association between
\end{abstract}


the IL-18 -137G/C polymorphism and RA showed pooled ORs and 95\%Cls for the homozygote (CC vs GG: OR $=0.699 ; 95 \% \mathrm{Cl}=0.364-1.342$ ) and heterozygote (CG vs GG: OR $=0.924 ; 95 \% \mathrm{Cl}=0.803-1.064)$ models. In summary, the current meta-analysis, which was based on the most current studies, showed that the $-607 \mathrm{~A} / \mathrm{C},-920 \mathrm{C} / \mathrm{T}$, and $-105 \mathrm{~A} / \mathrm{C}$ polymorphisms in IL-18 were significantly associated with increased RA risk. However, the $-137 \mathrm{C} / \mathrm{G}$ polymorphism was not associated with RA risk under any genetic model. More evidence is needed to support or deny such a conclusion.

Key words: IL-18; Polymorphism; Rheumatoid arthritis; Meta-analysis

\section{INTRODUCTION}

Rheumatoid arthritis (RA) is a common immune-mediated inflammatory disease characterized by the chronic inflammation of primarily synovial tissue, leading to joint destruction, functional disability, and even death (Harris, 1990). The precise etiology of RA is not completely clear, but a large number of studies have indicated that environmental and genetic factors are responsible for the susceptibility and phenotype (Perricone et al., 2011). More than 30 loci have been identified to be involved in RA pathogenesis by large genome-wide association studies (de Vries, 2011). Human leukocyte antigen (HLA) alleles, such as HLA-DRB1*01, HLA-DRB1*13, and HLA-DRB1*15, have been reported to be implicated in the pathogenesis of RA (Kurko et al., 2013). Non-HLA genes, such as peptidylarginine deiminase type 4, protein tyrosine phosphatase nonreceptor 22, interleukin-23 receptor, interleukin-1 $\beta$ (IL-1 3 ), macrophage migration inhibitory factor, tumor necrosis factor alpha (TNF- $\alpha$ ), and CD40, have also been shown to be involved in the pathogenesis of RA (Suzuki et al., 2013).

The imbalance of T helper type 1 and 2 cells (Th1 and Th2, respectively), which could be induced by IL-18, or cytokines has been observed to be involved in the occurrence and development of RA (Kawashima and Miossec, 2005). Previous studies have demonstrated that IL-18 is significantly elevated in sera, synovial fluid, and synovial tissues in osteoarthritic patients compared to healthy controls (Munakata et al., 2001). In the RA synovium, the expression of IL18 is associated with that of IL-1 $\beta$ and TNF- $\alpha$ and is correlated with the acute-phase response, demonstrating that IL-18 is an important proinflammatory cytokine that drives the local production of IL-1 $\beta$ and TNF- $\alpha$ in RA patients (Joosten et al., 2003). Dai et al. (2007) reported that IL-18 contributes to the development and maintenance of an acquired immune response in RA by promoting the differentiation and chemotaxis of T cells. All these reports indicate that IL-18 plays an important role in the pathogenesis of RA.

Many single nucleotide polymorphisms (SNPs) in the IL-18 gene region have been identified, including $-607 \mathrm{C} / \mathrm{A}$ and $-137 \mathrm{G} / \mathrm{C}$ in the IL-18 promoter regions and 148G/C and 105A/C in regulatory sequences. SNPs in the IL-18 promoter at positions -607C/A (rs1946518) and -137G/C (rs187238) have been repeatedly found to be associated with alterations in transcriptional activity (Giedraitis et al., 2001). Many studies concerning the association of IL-18 gene polymorphisms with RA have focused on these two polymorphisms, but results from these studies remain inconclusive and controversial. Meta-analysis is a powerful statistical method to combine the results from multiple studies in an effort to increase power, improve estimates of the size of the effect, and/or to resolve uncertainty when reports disagree. However, results from previous meta- 
analyses (published between 2012 and 2014) are still conflicting. Chen et al. (2012) conducted a meta-analysis and concluded that the -607A/C SNP but not the $-137 \mathrm{G} / \mathrm{C}$ SNP in IL-18 may confer susceptibility to RA in a Chinese population, but this cannot be extrapolated to all Asians. However, results from another meta-analysis demonstrated that the IL-18 137G/C SNP was a risk factor for RA (Wen et al., 2014). Ji and Lee (2013) performed a meta-analysis and concluded that no significant association was found between two IL-18 SNPs (-607C/A and -137G/C) and RA susceptibility in all subjects, even upon subgroup analysis. Cai et al. (2014) conducted a meta-analysis based on published studies between 2003 and 2012 and concluded that the IL$18-607 \mathrm{~A} / \mathrm{C}$ (not $-137 \mathrm{G} / \mathrm{C}$ ) polymorphism in the promoter region may be associated with RA risk. Considering these conflicting results, we conducted an updated meta-analysis to derive a more precise estimation of the association between IL-18 gene polymorphisms and RA risk.

\section{MATERIAL AND METHODS}

\section{Search strategy}

This meta-analysis was performed according to the methodology advocated by the PRISMA statement (Panic et al., 2013). All studies included in the meta-analysis were selected by searching PubMed, Ovid, Cochrane Library, EMBASE, and China Knowledge Resource Integrated Database up to May 1, 2015 using the following keywords: "(polymorphism OR variants OR mutation OR genotype) AND (IL-18 OR Interleukin-18) AND (rheumatoid arthritis OR RA)". There was no restriction on time period, sample size, population, or type of report. However, only studies published in English or Chinese were included. All eligible studies were retrieved and their references were checked for other relevant studies. The literature retrieval was performed in duplicate by two independent reviewers. When multiple publications reported on the same or overlapping data, the most recent or largest population was chosen. When a study reported the results on different subpopulations, each subpopulation was treated as a separate study in the meta-analysis.

\section{Inclusion criteria}

All of the studies met the following inclusion criteria: 1) case-control design; 2) association between IL-18 gene polymorphisms and RA risk; 3) application of standardized clinical or pathologic criteria for the diagnosis of RA; and 4) sufficient genotype distributions for calculation of odds ratios (ORs) with $95 \%$ confidence intervals $(95 \% \mathrm{Cls})$. The following were cause for exclusion: 1) not related to the IL-18 gene polymorphisms and RA risk; 2) not a primary case-control study; 3) no usable or insufficient genotype data reported; 4) studies where the allele frequency in the control population deviated from the Hardy-Weinberg equilibrium (HWE) at a $\mathrm{P}$ value equal to or less than 0.01; and 5) case reports, letter to editor, book chapters, or reviews. The study inclusion and exclusion procedures are summarized in Figure 1.

\section{Data extraction}

Two investigators independently extracted the data from all qualified studies according to the selection standard listed above. Discrepancies were resolved through discussion until 
agreement was reached. The following information was extracted: the first author's name, year of publication, the country in which the study was conducted, source of the control group, genotyping methods, sample size, number of cases and controls, risk allele frequency in controls, and results of HWE in controls.

171 articles relevant to the search terms

(Polymorphism OR variants OR mutation OR genotype) AND (IL-18 OR Interleukin-18) AND (Rheumatoid arthritis OR RA)

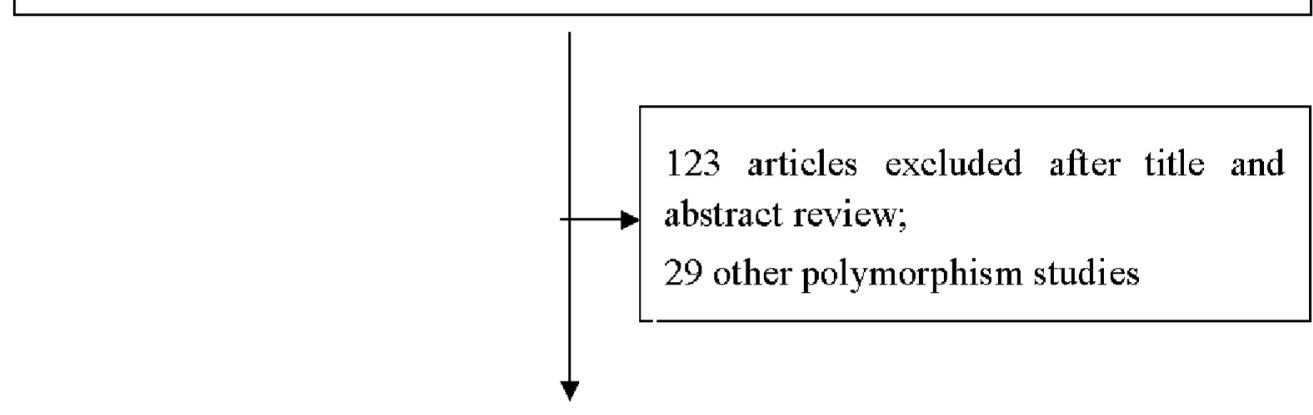

19 articles for full-text review

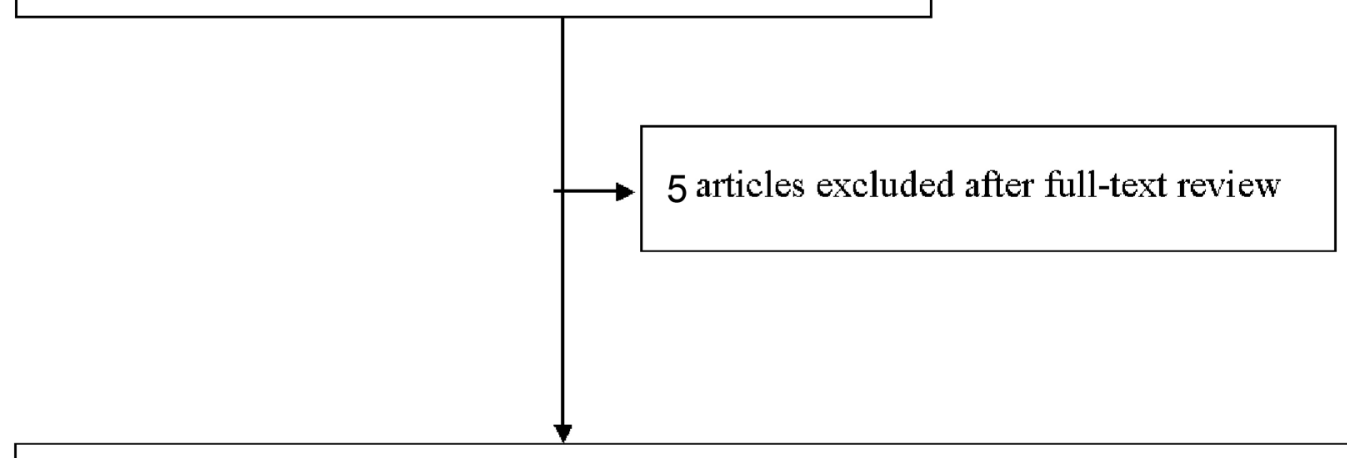

\section{4 articles included in this meta-analysis}

Figure 1. Inclusion and exclusion procedures for publications included in the meta-analysis.

\section{Statistical analysis}

All statistical analyses were performed using the STATA software 13.0 (StataCrop, College Station, TX, USA). Two-sided $P$ values less than 0.05 were considered to be statistically significant. The strength of the association between the IL-18 polymorphisms and RA risk was assessed by the ORs with $95 \% \mathrm{Cls}$. The pooled ORs were calculated for the homozygote, heterozygote, dominant, recessive, and additive models (Lee and Bae, 2015). We also conducted subgroup analysis by ethnicity, genotyping methods, and source of control. Cochran's Q-statistic and the $\mathrm{I}^{2}$ metric were conducted to assess heterogeneity between studies. We classified 
heterogeneity into three categories: high $\left(\mathrm{I}^{2}>50 \%\right)$, middle $\left(25<\mathrm{I}^{2}<50 \%\right)$, and low $\left(\mathrm{I}^{2}<25 \%\right)$ (Higgins and Thompson, 2002). If the heterogeneity test result resulted in $\mathrm{P}>0.1$, the pooled ORs were analyzed using the random-effects model; otherwise, the fixed effects model was used. The distribution of genotypes in the controls was checked for HWE (Salanti et al., 2005). Sensitivity analyses were also performed after sequential removal of each study (Wen et al., 2015). Last, publication bias was investigated by both Begg's funnel plot and the Egger linear regression test.

\section{RESULTS}

\section{Study characteristics}

A total of 171 relevant articles were initially identified from PubMed, Ovid, Cochrane Library, EMBASE, and China Knowledge Resource Integrated Database. After titles and abstracts were screened, 152 articles were excluded because of irrelevant data. The full texts of the remaining 19 records were carefully reviewed. Finally, 14 articles were included in the present meta-analysis (Sivalingam et al., 2003; Gracie et al., 2005; Rueda et al., 2005; Pawlik et al., 2006; Lee et al., 2007; Huang et al., 2007; Pawlik et al., 2009; Shi et al., 2011; Sugiura et al., 2011; Ying et al., 2011; Hashaad et al., 2012; Song et al., 2012; Farias et al., 2013; Gurram et al., 2014). All of the 14 articles were published between 2003 and 2014. Eleven articles were published in English and three were published in Chinese. Of the 14 eligible studies, 6 were conducted in Caucasian populations, 6 were in Asian populations, and 2 were in mixed populations. Thirteen studies were population-based and one was unclear. The genotype distributions in the controls for all studies were consistent with the Hardy-Weinberg equilibrium (Norton and Neel, 1965), except for three studies (Sivalingam et al., 2003; Rueda et al., 2005; Gurram et al., 2014). The characteristics of all included studies are summarized in Table 1.

\section{Results of the overall meta-analysis}

The results of the overall meta-analysis are summarized in Table 2. The IL-18 $-607 \mathrm{C} / \mathrm{A}$ polymorphism showed pooled ORs and $95 \% \mathrm{Cl}$ for the homozygote $(\mathrm{AA}$ vs CC: OR $=0.598 ; 95 \% \mathrm{Cl}$ $=0.395-0.907)$, heterozygote (AC vs CC: $O R=0.699 ; 95 \% \mathrm{Cl}=0.540-0.906)$, dominant $(\mathrm{AA}+\mathrm{AC}$ vs CC: $\mathrm{OR}=0.677 ; 95 \% \mathrm{Cl}=0.518-0.884)$, recessive $(\mathrm{AA}$ vs $\mathrm{AC}+\mathrm{CC}: \mathrm{OR}=0.771 ; 95 \% \mathrm{Cl}=0.558$ 1.065), and additive ( $\mathrm{A}$ vs $\mathrm{C}: \mathrm{OR}=0.766 ; 95 \% \mathrm{Cl}=0.633-0.927)$ models. The association between the IL-18 -137G/C polymorphism and RA showed pooled ORs and $95 \% \mathrm{Cl}$ for the homozygote (CC vs GG: OR = 0.699; 95\%Cl = 0.364-1.342), heterozygote (CG vs GG: OR $=0.924 ; 95 \% \mathrm{Cl}=0.803$ 1.064), dominant ( $\mathrm{CG}+\mathrm{CC}$ vs $\mathrm{GG}: \mathrm{OR}=0.810 ; 95 \% \mathrm{Cl}=0.633-1.038)$, recessive $(\mathrm{CC}$ vs $\mathrm{CG}+$ GG: OR $=0.725 ; 95 \% \mathrm{Cl}=0.383-1.371)$, and additive $(\mathrm{G}$ vs C: $\mathrm{OR}=0.777 ; 95 \% \mathrm{Cl}=0.583-1.036)$ models. The IL-18 -920C/T polymorphism showed pooled ORs and 95\%Cl for the homozygote (TT vs CC: $\mathrm{OR}=0.297 ; 95 \% \mathrm{Cl}=0.026-3.352)$, heterozygote $(\mathrm{CT}$ vs CC: $\mathrm{OR}=1.010 ; 95 \% \mathrm{Cl}=0.841-$ 1.214), dominant (CT + TT vs CC: OR $=0.905 ; 95 \% \mathrm{Cl}=0.761-1.076)$, recessive (TT vs CT + CC: $\mathrm{OR}=0.295 ; 95 \% \mathrm{Cl}=0.026-3.358)$, and additive $(\mathrm{T}$ vs $\mathrm{C}: \mathrm{OR}=0.848 ; 95 \% \mathrm{Cl}=0.759-0.949)$ models (Figures 2 and 3). 
L.L. Li et al.

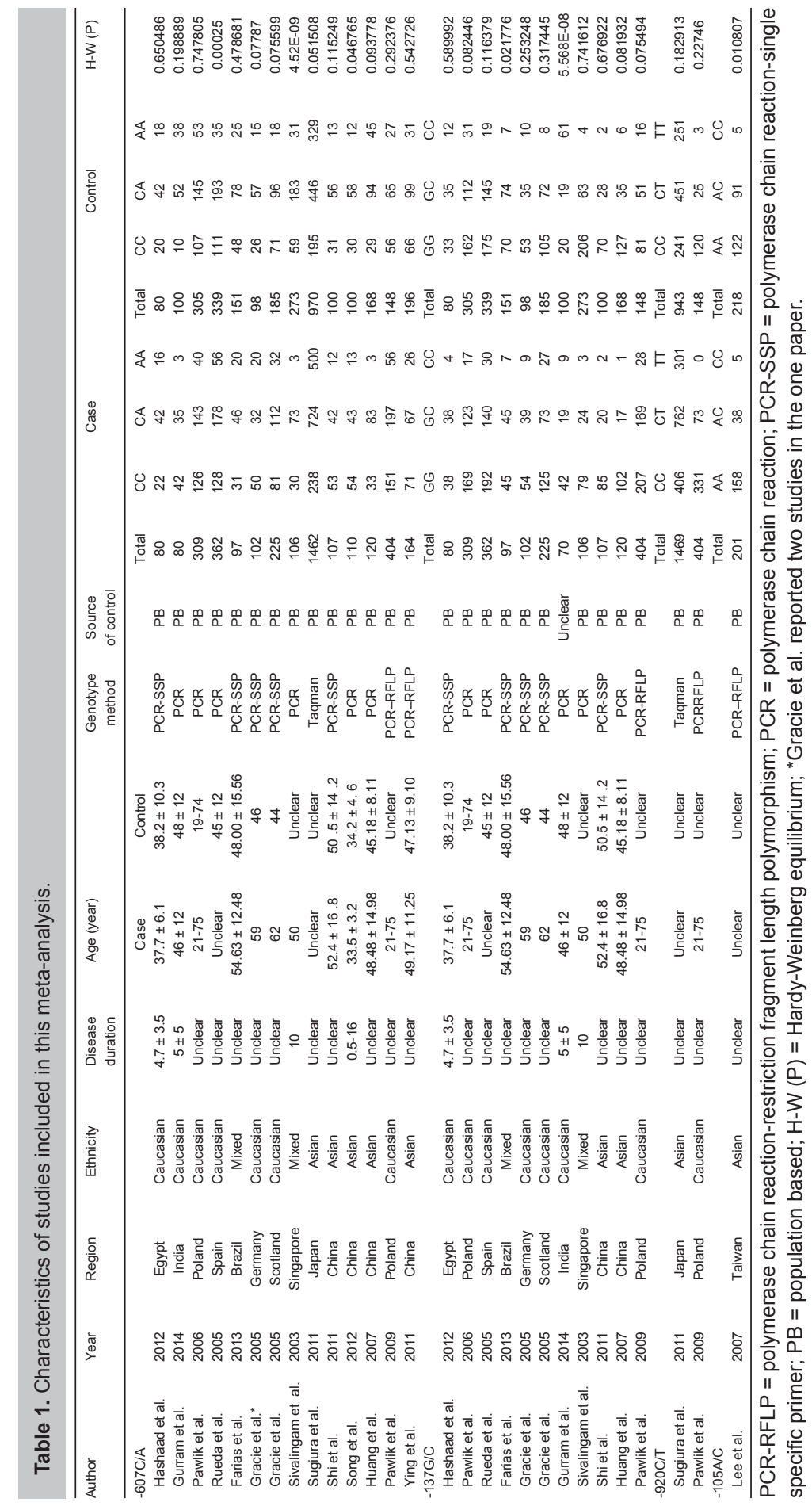




\section{Table 2. Results of the overall meta-analysis.}

\begin{tabular}{|c|c|c|c|}
\hline Polymorphism & OR $(95 \% \mathrm{Cl})$ & Heterogeneity & $Z$ and $P$ values \\
\hline \multicolumn{4}{|l|}{ IL-18 -607C/A } \\
\hline AA vs CC & $0.598(0.395-0.907)$ & chi-squared $=74.16$ (d.f. $=13$ ), $P=0.000 \mathrm{l}$-squared $=82.5 \%$ & $Z=2.42, P=0.015$ \\
\hline $\mathrm{AC}$ vs $\mathrm{CC}$ & $0.699(0.540-0.906)$ & chi-squared $=57.34$ (d.f. $=13$ ), $P=0.000 \mathrm{I}$-squared $=77.3 \%$ & $Z=2.70, P=0.007$ \\
\hline$A A+A C$ vs $C C$ & $0.677(0.518-0.884)$ & chi-squared $=67.95$ (d.f. $=13$ ), $P=0.000 \mathrm{I}$-squared $=80.9 \%$ & $Z=2.86, P=0.004$ \\
\hline$A A$ vs $A C+C C$ & $0.771(0.558-1.065)$ & chi-squared $=56.36$ (d.f. $=13$ ), $P=0.000$ l-squared $=76.9 \%$ & $Z=1.58, P=0.114$ \\
\hline A vs $\mathrm{C}$ & $0.766(0.633-0.927)$ & chi-squared $=81.36$ (d.f. $=13$ ), $P=0.000 \mathrm{l}$-squared $=84.0 \%$ & $Z=2.74, P=0.006$ \\
\hline \multicolumn{4}{|l|}{ IL-18 -137G/C } \\
\hline CC vs GG & $0.699(0.364-1.342)$ & chi-squared $=50.47$ (d.f. $=10$ ), $P=0.000 \mathrm{l}$-squared $=80.2 \%$ & $Z=1.08, P=0.282$ \\
\hline CG vs GG & $0.924(0.803-1.064)$ & chi-squared $=9.89($ d.f. $=10), P=0.450 \mathrm{I}$-squared $=0.0 \%$ & $Z=1.09, P=0.274$ \\
\hline$C G+C C$ vs $G G$ & $0.810(0.633-1.038)$ & chi-squared $=30.68$ (d.f. $=10), P=0.001 \mathrm{l}$-squared $=67.4 \%$ & $Z=1.67, P=0.095$ \\
\hline$C C$ vs $C G+G G$ & $0.725(0.383-1.371)$ & chi-squared $=51.03$ (d.f. $=10), P=0.000 \mathrm{I}$-squared $=80.4 \%$ & $Z=0.99, P=0.322$ \\
\hline C vs G & $0.777(0.583-1.036)$ & chi-squared $=66.08$ (d.f. $=10), P=0.000 \mathrm{I}$-squared $=84.9 \%$ & $Z=1.72, P=0.086$ \\
\hline \multicolumn{4}{|c|}{ 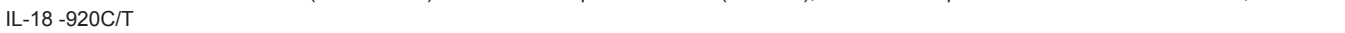 } \\
\hline TT vs CC & $0.297(0.026-3.352)$ & chi-squared $=2.98$ (d.f. $=1$ ), $P=0.085 \mathrm{I}$-squared $=66.4 \%$ & $Z=0.98, P=0.326$ \\
\hline CT vs CC & $1.010(0.841-1.214)$ & chi-squared $=0.04$ (d.f. $=1), P=0.844$ I-squared $=0.0 \%$ & $Z=0.11, P=0.913$ \\
\hline $\mathrm{CT}+\mathrm{TT}$ vs $\mathrm{CC}$ & $0.905(0.761-1.076)$ & chi-squared $=0.04$ (d.f. $=1), P=0.849$ I-squared $=0.0 \%$ & $Z=1.13, P=0.257$ \\
\hline TT vs $C T+C C$ & $0.295(0.026-3.358)$ & chi-squared $=3.00$ (d.f. $=1), P=0.083$ I-squared $=66.7 \%$ & $Z=0.98, P=0.325$ \\
\hline T vs C & $0.848(0.759-0.949)$ & chi-squared $=0.00$ (d.f. $=1), P=0.997 \mathrm{I}$-squared $=0.0 \%$ & $Z=2.88, P=0.004$ \\
\hline
\end{tabular}

$\mathrm{OR}=$ odds ratio; d.f. = degrees of freedom; $\mathrm{Cl}=$ confidence interval

Study

ID
$\%$

OR $(95 \% \mathrm{Cl}) \quad$ Weight

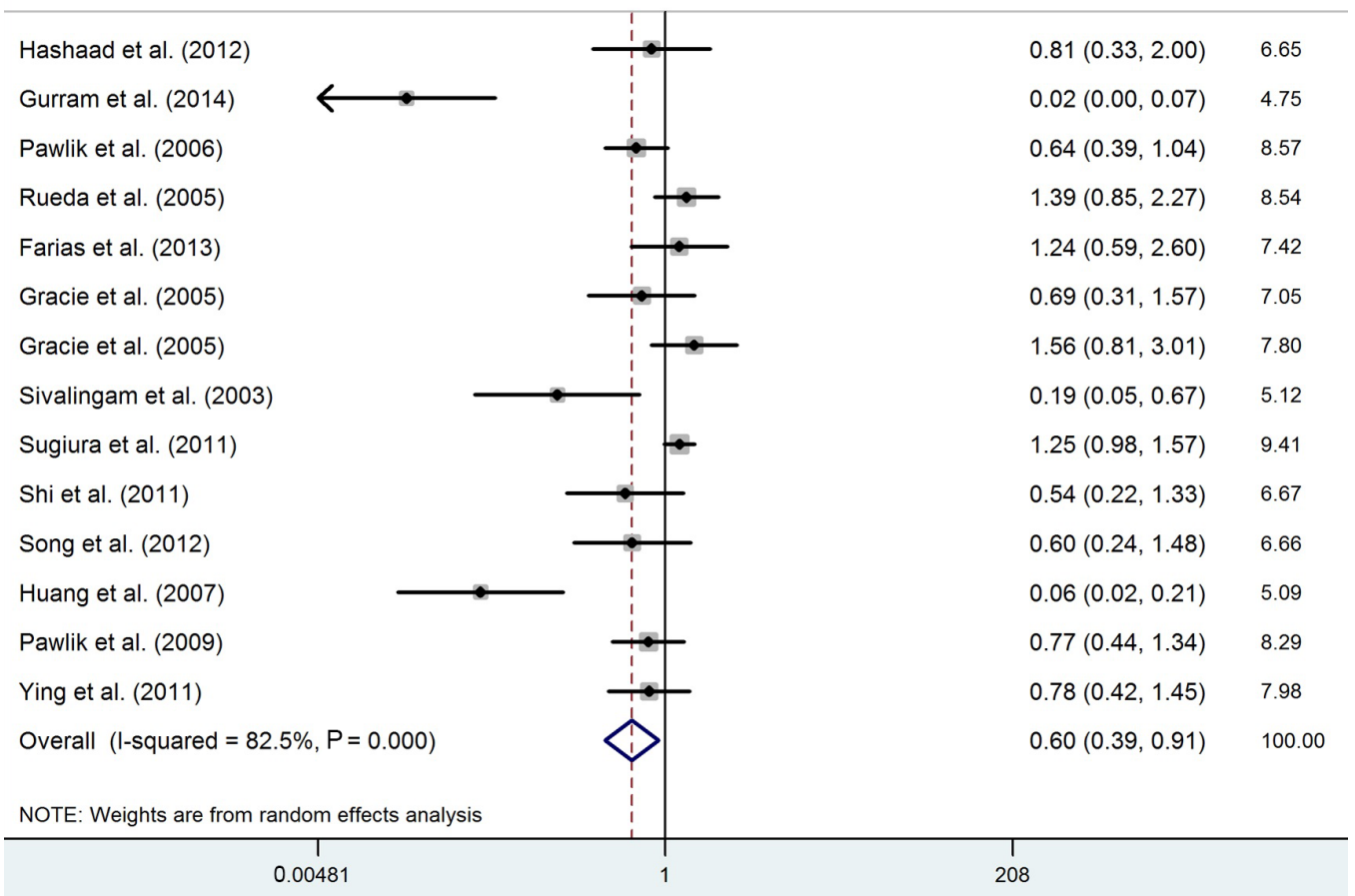

Figure 2. Random effect forest plot of homozygote model (AA vs CC) of IL-18 -607A/C polymorphism. 
Study

$\%$

ID

OR $(95 \% \mathrm{Cl}) \quad$ Weight

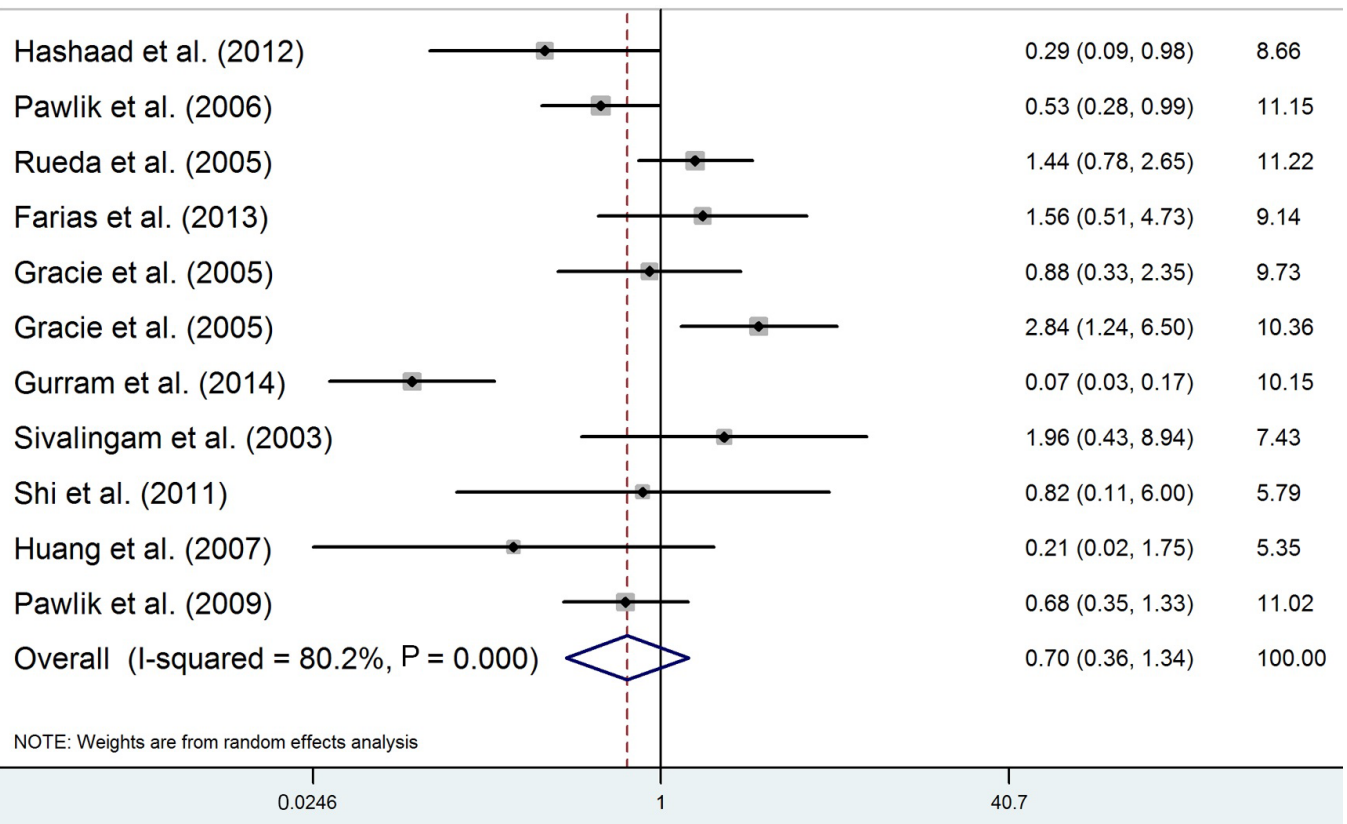

Figure 3. Random effect forest plot of homozygote model (CC vs GG) of IL-18 -137C/G polymorphism.

\section{Sub-group analysis}

We next performed a sub-group analysis stratified by ethnicity. For the IL-18-607C/A polymorphism, 7 studies were conducted in Caucasian populations, 5 studies were conducted in Asian populations, and 2 were conducted in mixed populations. For the IL-18 -137G/C gene polymorphism, 7 studies were conducted in Caucasian populations, 2 studies were conducted in Asian populations, and 2 were conducted in mixed populations. For the IL-18 $-920 \mathrm{C} / \mathrm{T}$ polymorphism, one study was conducted in a Caucasian population and one study was conducted in an Asian population. The results of the sub-group analysis are shown in detail in Table 3.

\section{Test of heterogeneity and sensitivity analysis}

We assessed the source of heterogeneity by region, publication year, control source, and sample size. However, we did not observe any sources that contributed to substantial heterogeneity. Sensitivity analyses were conducted to ascertain the primary origin of the heterogeneity. No individual study significantly affected the pooled OR because no substantial change was found (Figures 4 and 5). 
Table 3. Results of sub-group analysis stratified by ethnicity.

\begin{tabular}{|c|c|c|c|c|c|c|}
\hline Polymorphism & $\mathrm{N}$ & OR $(95 \% \mathrm{Cl})$ & OR $(95 \% \mathrm{Cl})$ & OR $(95 \% \mathrm{Cl})$ & OR $(95 \% \mathrm{Cl})$ & OR $(95 \% \mathrm{Cl})$ \\
\hline $\begin{array}{c}\text { IL-18 -607C/A } \\
\text { Ethnicity }\end{array}$ & & $\mathrm{AA}$ vs $\mathrm{CC}$ & $\mathrm{AC}$ vs $\mathrm{CC}$ & $\mathrm{AA}+\mathrm{AC}$ vs $\mathrm{CC}$ & $A A$ vs $A C+C C$ & A vs C \\
\hline Caucasian & 7 & $0.626(0.327-1.199)$ & $0.666(0.450-0.986)$ & $0.644(0.421-0.984)$ & $0.817(0.486-1.374)$ & $0.750(0.539-1.045)$ \\
\hline Mixed & 2 & $0.521(0.081-3.341)$ & $0.839(0.570-1.234)$ & $0.823(0.566-1.195)$ & $0.587(0.102-3.387)$ & $0.881(0.599-1.296)$ \\
\hline Asian & 5 & $0.526(0.242-1.141)$ & $0.674(0.400-1.137)$ & $0.647(0.388-1.078)$ & $0.681(0.373-1.245)$ & $0.730(0.523-1.017)$ \\
\hline Overall & 14 & $0.598(0.395-0.907)$ & $0.699(0.540-0.906)$ & $0.677(0.518-0.884)$ & $0.771(0.558-1.065)$ & $0.766(0.633-0.927)$ \\
\hline $\begin{array}{c}\text { IL-18 -137G/C } \\
\text { Ethnicity }\end{array}$ & & CC vs GG & CG vs GG & $\mathrm{CG}+\mathrm{CC}$ vs $\mathrm{GG}$ & $C C$ vs $C G+G G$ & C vs G \\
\hline Caucasian & 7 & $0.611(0.269-1.386)$ & $0.970(0.825-1.140)$ & $0.812(0.580-1.137)$ & $0.631(0.285-1.396)$ & $0.753(0.508-1.116)$ \\
\hline Mixed & 2 & $1.685(0.687-4.134)$ & $0.969(0.665-1.412)$ & $1.024(0.712-1.473)$ & $1.713(0.711-4.127)$ & $1.080(0.800-1.456)$ \\
\hline Asian & 2 & $0.434(0.102-1.858)$ & $0.597(0.378-0.942)$ & $0.574(0.369-0.891)$ & $0.485(0.114-2.066)$ & $0.591(0.397-0.881)$ \\
\hline Overall & 11 & $0.699(0.364-1.342)$ & $0.924(0.803-1.064)$ & $0.810(0.633-1.038)$ & $0.725(0.383-1.371)$ & $0.777(0.583-1.036)$ \\
\hline $\begin{array}{l}\text { IL-18 -920C/T } \\
\text { Ethnicity }\end{array}$ & & TT vs CC & CT vs CC & $\mathrm{CT}+\mathrm{TT}$ vs CC & $\mathrm{TT}$ vs $\mathrm{CT}+\mathrm{CC}$ & T vs C \\
\hline Caucasian & 1 & $0.052(0.003-1.013)$ & $1.059(0.642-1.745)$ & $0.945(0.583-1.532)$ & $0.051(0.003-1.001)$ & $0.849(0.545-1.322)$ \\
\hline Asian & 1 & $0.712(0.565-0.897)$ & $1.003(0.823-1.222)$ & $0.899(0.747-1.082)$ & $0.710(0.586-0.861)$ & $0.848(0.756-0.953)$ \\
\hline Overall & 2 & $0.297(0.026-3.352)$ & $1.010(0.841-1.214)$ & $0.905(0.761-1.076)$ & $0.295(0.026-3.358)$ & $0.848(0.759-0.949)$ \\
\hline
\end{tabular}

\section{Meta-analysis random-effects estimates (linear form) Study omitted}

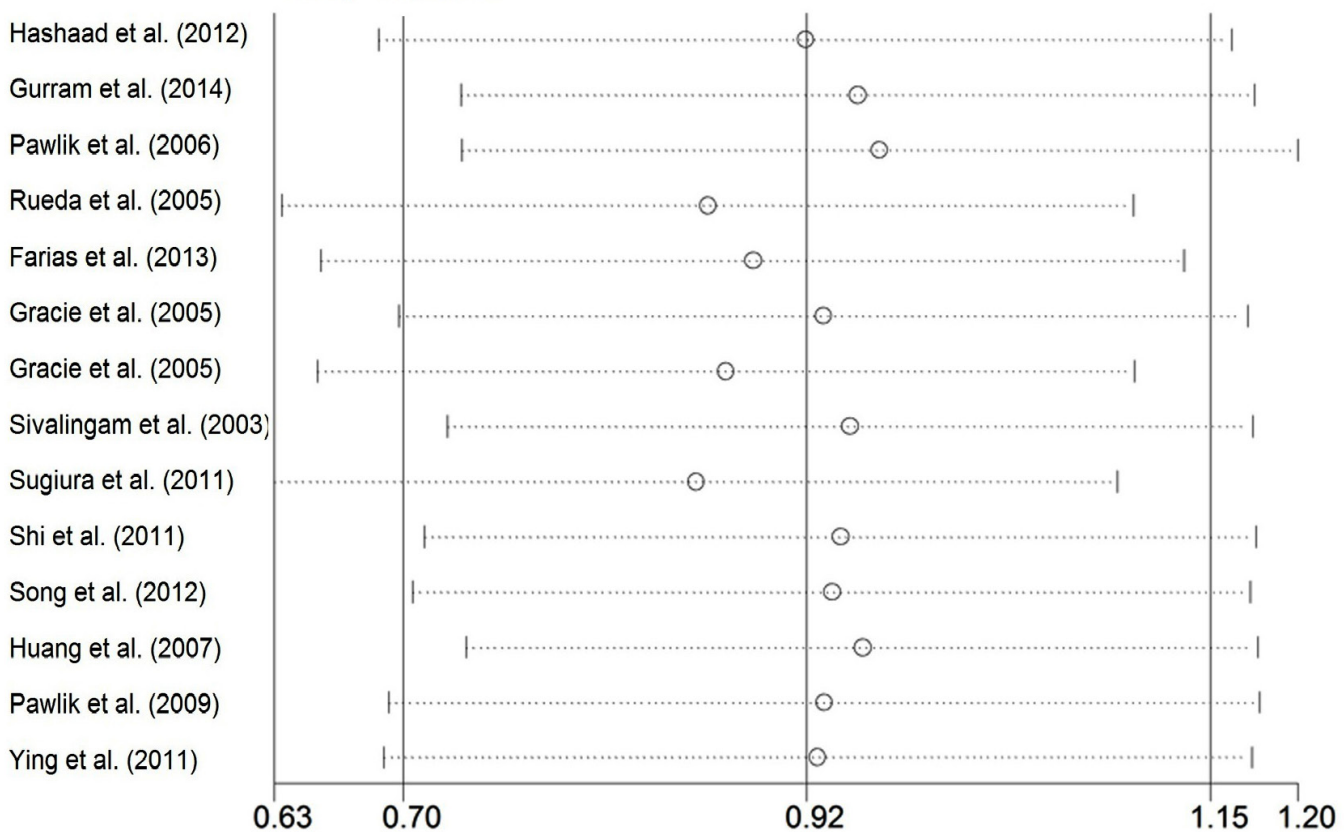

Figure 4. Sensitivity analysis for IL-18 -607A/C polymorphism.

\section{Publication bias}

Funnel plots were generated to assess publication bias. The Begg test was performed to statistically evaluate funnel plot symmetry. The results showed no publication bias: Begg's test 
$\operatorname{Pr}>|Z|=0.052$ for the IL-18 -137G/C polymorphism and $\operatorname{Pr}>|Z|=0.055$ for the IL-18 -607C/A polymorphism. The results suggest that publication bias was not a factor in this meta-analysis (Figures 6 and 7 ).

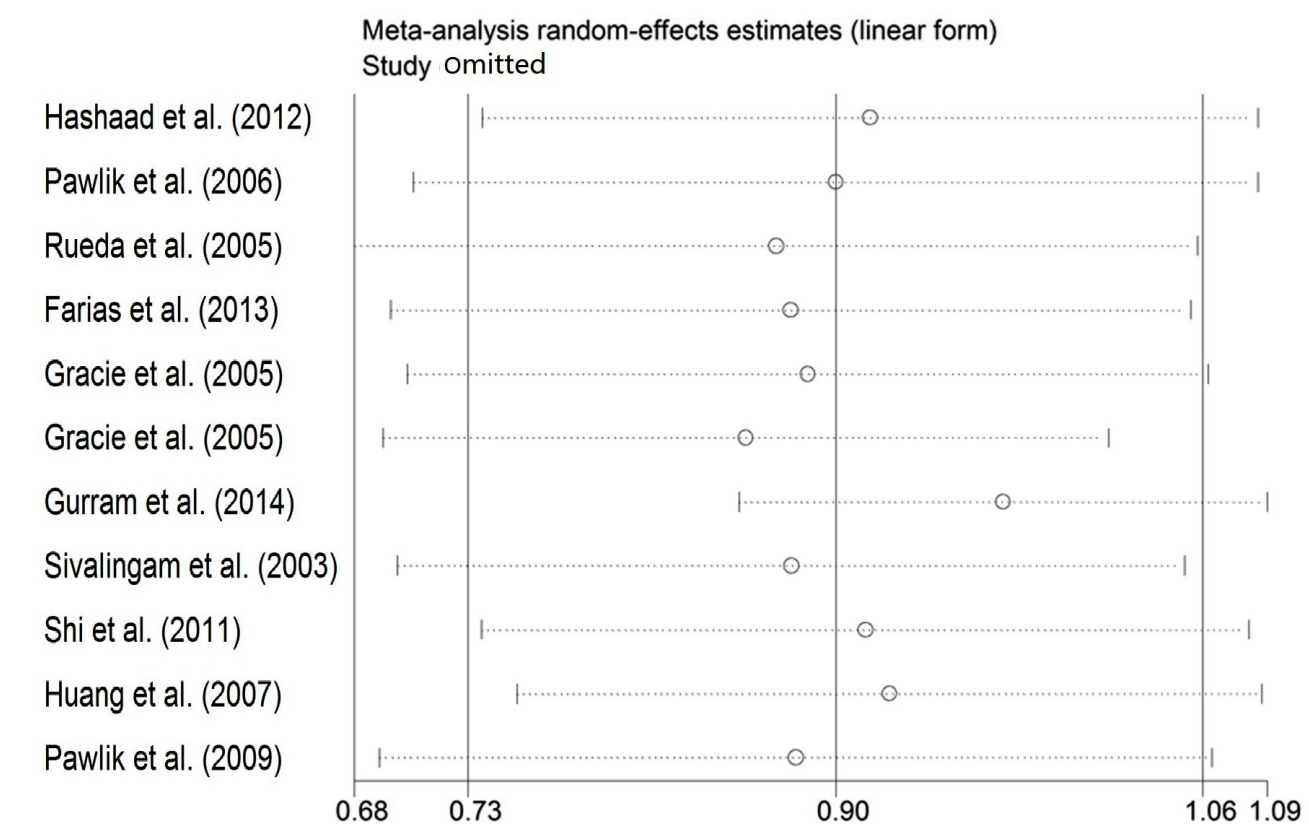

Figure 5. Sensitivity analysis for IL-18 -137C/G polymorphism.

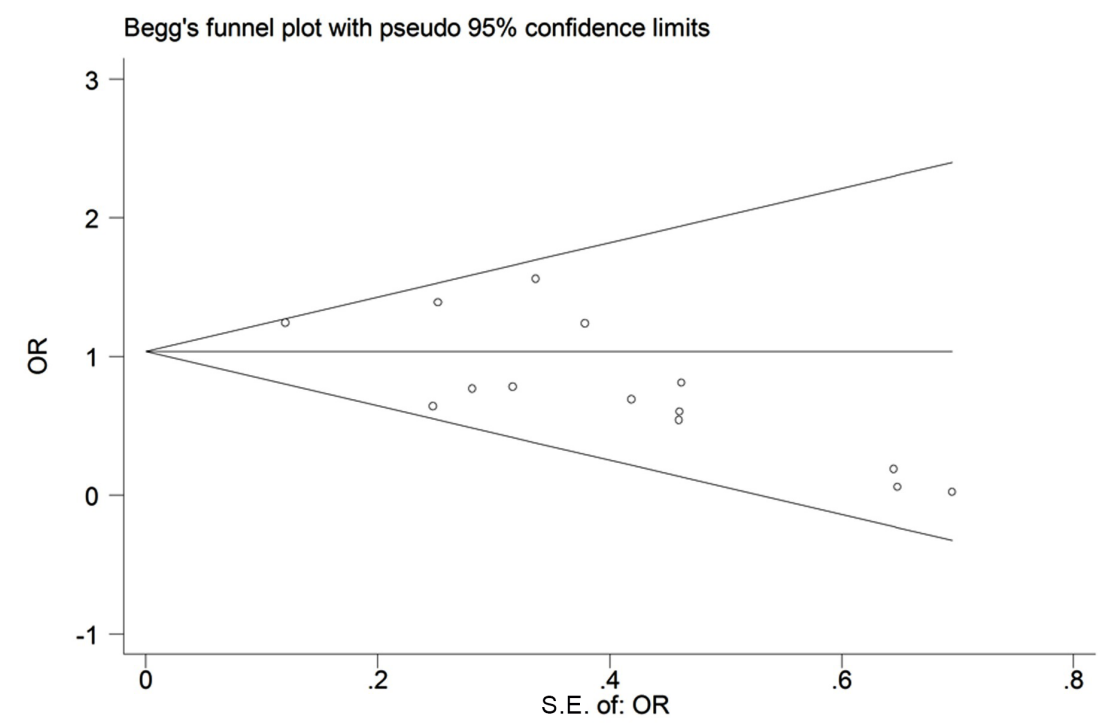

Figure 6. Publication bias test for IL-18 -607 A/C polymorphism. OR = odds ratio; S.E. = standard error. 


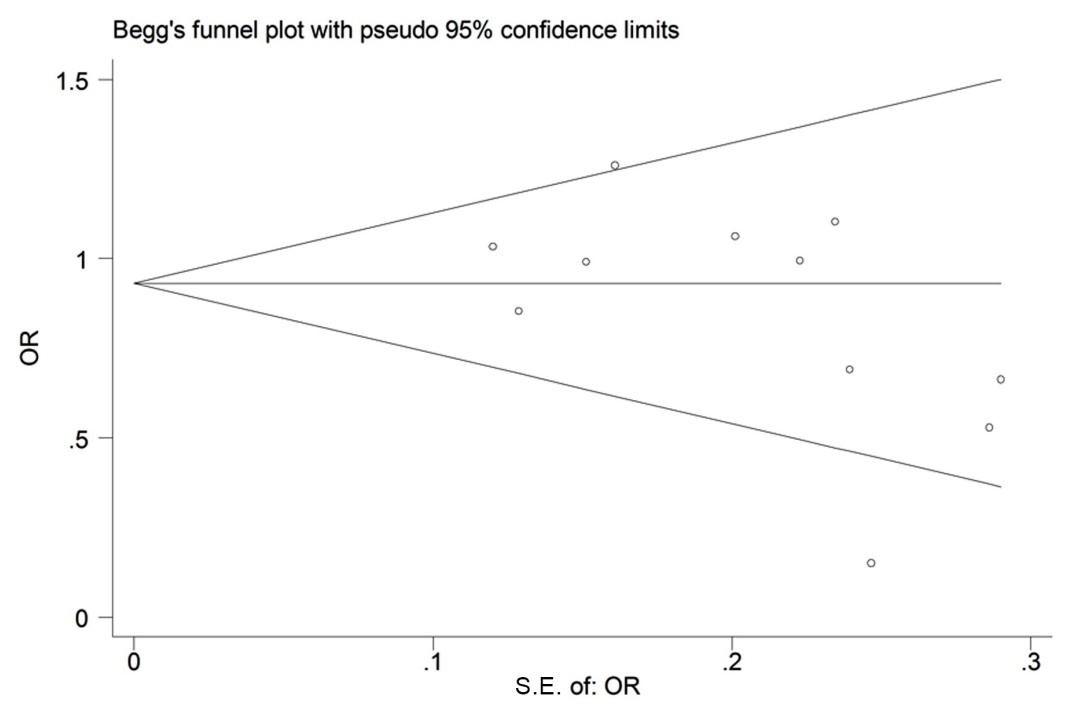

Figure 7. Publication bias test for IL-18 $-137 \mathrm{C} / \mathrm{G}$ polymorphism. OR = odds ratio; S.E. = standard error.

\section{DISCUSSION}

Previous studies have demonstrated that the imbalance of Th1 and Th2 cells plays an important role in the induction and development of RA. IL-18 can promote upregulation of Th1 cells and inhibit Th2 cells in RA patients, which results in a greater imbalance of Th1 and Th2 cells (Shao et al., 2009). The IL-18 promoter region regulates IL-18 protein expression. Two SNPs in this region are $-137 \mathrm{C} / \mathrm{G}$ and $-607 \mathrm{~A} / \mathrm{C}$, which are located at the binding sites for cAMP responseelement binding transcription factor and the H4TF-1 nuclear factor, respectively. Higher frequencies of $A$ alleles at position -607 and/or higher frequencies of $C$ alleles at position -137 were thought to have some protective effects against the development of RA.

Many studies have explored the association between IL-18 gene polymorphisms and RA risk, but results from these studies remain inconclusive and controversial. Meta-analysis is regarded as a powerful tool to more precisely define the effects of select genetic polymorphisms on the risk for disease and to identify potentially important sources of between-study heterogeneity. However, results from previous meta-analyses are still conflicting. Hence, we performed this meta-analysis including all available studies to provide the most comprehensive assessment of the association between the IL-18 gene polymorphisms and RA risk. For the IL-18 -607A/C polymorphism, there were 14 studies with 3728 cases and 3213 controls included in our meta-analysis. For the $-137 \mathrm{C} / \mathrm{G}$ polymorphism, there were 11 studies with 1982 cases and 1947 controls included. The results from this meta-analysis suggest that the IL-18-607A/C and $-920 \mathrm{C} / \mathrm{T}$ polymorphisms are significantly associated with increased RA risk. However, for the $-137 \mathrm{C} / \mathrm{G}$ polymorphism, we failed to find any association with RA risk under all genetic models. Additionally, for the IL-18 -105A/C polymorphism, there was just one study included in this meta-analysis and the results of this study provided genetic evidence that the IL-18 -105A/C polymorphism may play a role in RA (Lee et al., 2007).

Of course, we should be careful to conclude that there is no association between the $-137 \mathrm{C} / \mathrm{G}$ polymorphism and RA risk merely on the basis of the negative results in this study. If a 
putative genetic association is of a small magnitude with point estimates of less than 1.5 , the small and underpowered studies may be unable to identify true genetic associations (loannidis, 2003; loannidis et al., 2006; Hindorff et al., 2009). Thus, more evidence is needed to support or deny such an association. By means of a meta-analysis, a statistical technique for combining the results from independent studies, we drew a more reliable conclusion on the influence of IL-18 polymorphisms on RA risk. However, as RA might be a result of multiple factors, future research should focus not only on individual genes, but also on gene-gene interactions.

Meta-analysis is regarded as a useful method for synthesizing data from all eligible studies to obtain greater statistical power. However, several potential limitations of this metaanalysis should be noted: 1) although the funnel plot and the Begg test showed no publication bias, selection bias may have occurred because only studies published in English or Chinese were selected; and 2) there was significant heterogeneity. However, our meta-analysis has some clear advantages: 1) the most recent studies were examined; 2) we performed a sub-group analysis stratified by ethnicity; 3 ) sensitivity analysis showed no individual study had a marked effect on the overall results; 4) the scientific search and selection method significantly increased the applicability of this meta-analysis; and 5) no publication bias was detected.

In summary, this meta-analysis, which is based on the most current information, showed that the $-607 \mathrm{~A} / \mathrm{C},-920 \mathrm{C} / \mathrm{T}$ and $-105 \mathrm{~A} / \mathrm{C}$ polymorphisms in IL-18 were significantly associated with increased RA risk. However, the $-137 \mathrm{C} / \mathrm{G}$ polymorphism was not associated with RA risk under any genetic model. Of course, more evidence is needed to support or deny such a conclusion.

\section{Conflicts of interest}

The authors declare no conflict of interest.

\section{ACKNOWLEDGMENTS}

We thank all authors of primary studies included in our meta-analyses. There was no funding support.

\section{REFERENCES}

Cai LP, Zhou LJ, Lu SY, Liang YE, et al. (2014). Association of IL-18 promoter gene polymorphisms with rheumatoid arthritis: a meta-analysis. Mol. Biol. Rep. 41: 8211-8217.http://dx.doi.org/10.1007/s11033-014-3723-3

Chen S, Jiang F, Ren J, Liu J, et al. (2012). Association of IL-18 polymorphisms with rheumatoid arthritis and systemic lupus erythematosus in Asian populations: a meta-analysis. BMC Med. Genet. 13: 107.http://dx.doi.org/10.1186/1471-2350-13-107

Dai SM, Shan ZZ, Xu H and Nishioka K (2007). Cellular targets of interleukin-18 in rheumatoid arthritis. Ann. Rheum. Dis. 66: 1411-1418.http://dx.doi.org/10.1136/ard.2006.067793

de Vries R (2011). Genetics of rheumatoid arthritis: time for a change! Curr. Opin. Rheumatol. 23: $227-232$. http://dx.doi.org/10.1097/BOR.0b013e3283457524

Farias TD, Canto LM, Medeiros MD, Sereia AF, et al. (2013). Lack of association between interleukin-18 polymorphisms and rheumatoid arthritis. Rev. Bras. Reumatol. 53: 199-205.

Giedraitis V, He B, Huang WX and Hillert J (2001). Cloning and mutation analysis of the human IL-18 promoter: a possible role of polymorphisms in expression regulation. J. Neuroimmunol. 112: 146-152. http://dx.doi.org/10.1016/S0165-5728(00)00407-0

Gracie JA, Koyama N, Murdoch J, Field M, et al. (2005). Disease association of two distinct interleukin-18 promoter polymorphisms in Caucasian rheumatoid arthritis patients. Genes Immun. 6: 211-216. http://dx.doi.org/10.1038/sj.gene.6364183 
Gurram VC, Polipalli SK, Karra VK, Puppala M, et al. (2014). Genetic polymorphism of interleukin-18 gene promoter region in rheumatoid arthritis patients from southern India. J. Clin. Diagn. Res. 8: SC01-SC04.

Harris ED, Jr. (1990). Rheumatoid arthritis. Pathophysiology and implications for therapy. N. Engl. J. Med. 322: 1277-1289. http://dx.doi.org/10.1056/NEJM199005033221805

Hashaad NI, El-Din MS, Moustafa EF and Abo Elazem AA (2012). Interleukin-18 promoter polymorphisms in Egyptian patients with rheumatoid arthritis. Egypt. J. Immunol. 19: 13-24.

Higgins JP and Thompson SG (2002). Quantifying heterogeneity in a meta-analysis. Stat. Med. 21: 1539-1558. http://dx.doi.org/10.1002/sim.1186

Hindorff LA, Sethupathy P, Junkins HA, Ramos EM, et al. (2009). Potential etiologic and functional implications of genome-wide association loci for human diseases and traits. Proc. Natl. Acad. Sci. USA 106: 9362-9367. http://dx.doi.org/10.1073/pnas.0903103106

Huang XZ, Zhuang JH, Ren YG, Zhou LJ, et al. (2007). [Association of interleukin-6 and interleukin-18 gene polymorphism with rheumatoid arthritis in Guangdong Han population]. Nan Fang Yi Ke Da Xue Xue Bao 27: 1661-1664.

Ioannidis JP (2003). Genetic associations: false or true? Trends Mol. Med. 9: 135-138. http://dx.doi.org/10.1016/S1471-4914(03)00030-3

Ioannidis JP, Trikalinos TA and Khoury MJ (2006). Implications of small effect sizes of individual genetic variants on the design and interpretation of genetic association studies of complex diseases. Am. J. Epidemiol. 164: 609-614. http://dx.doi.org/10.1093/aje/kwj259

Ji JD and Lee WJ (2013). Interleukin-18 gene polymorphisms and rheumatoid arthritis: a meta-analysis. Gene 523: 27-32. http://dx.doi.org/10.1016/i.gene.2013.03.132

Joosten LA, Radstake TR, Lubberts E, van den Bersselaar LA, et al. (2003). Association of interleukin-18 expression with enhanced levels of both interleukin-1beta and tumor necrosis factor alpha in knee synovial tissue of patients with rheumatoid arthritis. Arthritis Rheum. 48: 339-347.http://dx.doi.org/10.1002/art.10814

Kawashima M and Miossec P (2005). mRNA quantification of T-bet, GATA-3, IFN-gamma, and IL-4 shows a defective Th1 immune response in the peripheral blood from rheumatoid arthritis patients: link with disease activity. J. Clin. Immunol. 25: 209-214.http://dx.doi.org/10.1007/s10875-005-4092-4

Kurkó J, Besenyei T, Laki J, Glant TT, et al. (2013). Genetics of rheumatoid arthritis - a comprehensive review. Clin. Rev. Allergy Immunol. 45: 170-179.http://dx.doi.org/10.1007/s12016-012-8346-7

Lee CC, Lin WY, Wan L, Tsai Y, et al. (2007). Interleukin-18 gene polymorphism, but not interleukin-2 gene polymorphism, is associated with rheumatoid arthritis. Immunogenetics 59: 433-439.http://dx.doi.org/10.1007/s00251-007-0212-z

Lee YH and Bae SC (2015). Associations between TNF- $\alpha$ polymorphisms and susceptibility to rheumatoid arthritis and vitiligo: a meta-analysis. Genet. Mol. Res. 14: 5548-5559.http://dx.doi.org/10.4238/2015.May.25.6

Munakata T, Uzuki M, Shimamura T and Sawai T (2001). [Dynamics of interleukin (IL)-18 in serum, synovial fluid and synovial membrane in the patients with rheumatoid arthritis]. Ryumachi 41: 625-634.

Norton HW and Neel JV (1965). Hardy-Weinberg equilibrium and promitive populations. Am. J. Hum. Genet. 17: 91-92.

Panic N, Leoncini E, de Belvis G, Ricciardi W, et al. (2013). Evaluation of the endorsement of the preferred reporting items for systematic reviews and meta-analysis (PRISMA) statement on the quality of published systematic review and metaanalyses. PLoS One 8: e83138.http://dx.doi.org/10.1371/journal.pone.0083138

Pawlik A, Kurzawski M, Czerny B, Gawronska-Szklarz B, et al. (2006). Interleukin-18 promoter polymorphism in patients with rheumatoid arthritis. Tissue Antigens 67: 415-418.http://dx.doi.org/10.1111/j.1399-0039.2006.00582.x

Pawlik A, Kurzawski M, Drozdzik M, Dziedziejko V, et al. (2009). Interleukin-18 gene (IL18) promoter polymorphisms in patients with rheumatoid arthritis. Scand. J. Rheumatol. 38: 159-165.http://dx.doi.org/10.1080/03009740802600748

Perricone C, Ceccarelli F and Valesini G (2011). An overview on the genetic of rheumatoid arthritis: a never-ending story. Autoimmun. Rev. 10: 599-608.http://dx.doi.org/10.1016/j.autrev.2011.04.021

Rueda B, González-Gay MA, Mataran L, López-Nevot MA, et al. (2005). Interleukin-18-promoter polymorphisms are not relevant in rheumatoid arthritis. Tissue Antigens 65: 544-548.http://dx.doi.org/10.1111/j.1399-0039.2005.00408.x

Salanti G, Amountza G, Ntzani EE and loannidis JP (2005). Hardy-Weinberg equilibrium in genetic association studies: an empirical evaluation of reporting, deviations, and power. Eur. J. Hum. Genet. 13: 840-848. http://dx.doi.org/10.1038/sj.ejhg.5201410

Shao XT, Feng L, Gu LJ, Wu LJ, et al. (2009). Expression of interleukin-18, IL-18BP, and IL-18R in serum, synovial fluid, and synovial tissue in patients with rheumatoid arthritis. Clin. Exp. Med. 9: 215-221.http://dx.doi.org/10.1007/s10238-009-0036-2

Shi P, Xiao LS, Fei Y and Yu F (2011). Polymorphisms of IL-18 gene in rheumatoid arthitis and its association with rheumatoid factor or anti-cyclic citrulliated peptide antibody in Han population of Guizhou of China. Clin. Focus 26: 289-295.

Sivalingam SP, Yoon KH, Koh DR and Fong KY (2003). Single-nucleotide polymorphisms of the interleukin-18 gene promoter region in rheumatoid arthritis patients: protective effect of AA genotype. Tissue Antigens 62: 498-504. http://dx.doi.org/10.1046/j.1399-0039.2003.00137.x 
Song X-Q, Yi Z-H, Wang X-Q, Liu R-K, et al. (2012). Detection of IL-18 gene promoter -607C/C polymorphisms in Han population with rheumatoid arthritis in the South of Henan Province. J. Xinyang Norm. Univ. Nat. Sci. Ed. 26: 329-332.

Sugiura T, Kawaguchi Y, Ikari K, Ichida H, et al. (2011). Interleukin-18 promoter polymorphisms in Japanese patients with rheumatoid arthritis: protective effect of the T allele and T/T genotype at rs360722. Mod. Rheumatol. 21: 359-364. http://dx.doi.org/10.3109/s10165-010-0399-y

Suzuki T, Ikari K, Yano K, Inoue E, et al. (2013). PADI4 and HLA-DRB1 are genetic risks for radiographic progression in RA patients, independent of ACPA status: results from the IORRA cohort study. PLoS One 8: e61045. http://dx.doi.org/10.1371/journal.pone.0061045

Wen D, Liu J, Du X, Dong JZ, et al. (2014). Association of interleukin-18 (-137G/C) polymorphism with rheumatoid arthritis and systemic lupus erythematosus: a meta-analysis. Int. Rev. Immunol. 33: 34-44. http://dx.doi.org/10.3109/08830185.2013.816699

Wen SW, Zhang YF, Li Y, Liu ZX, et al. (2015). Association of miR-21 with esophageal cancer prognosis: a meta-analysis. Genet. Mol. Res. 14: 6578-6582.http://dx.doi.org/10.4238/2015.June.12.12

Ying B, Shi Y, Pan X, Song X, et al. (2011). Association of polymorphisms in the human IL-10 and IL-18 genes with rheumatoid arthritis. Mol. Biol. Rep. 38: 379-385.http://dx.doi.org/10.1007/s11033-010-0119-x 